\title{
Morphological Study of Splenic Notches and Fissures
}

\section{A. Thamaraiselvi ${ }^{1}$, Precila Infant Vincy. ${ }^{*}{ }^{*}$, T. L. Anbumani ${ }^{3}$.}

${ }^{1}$ Assistant Professor, Karpaga Vinayaga Institute of Medical Sciences, Madurantakam Taluk, Chengalpet Dt, Tamilnadu, India.

${ }^{* 2}$ Post graduate, Karpaga Vinayaga Institute of Medical Sciences, Madurantakam Taluk, Chengalpet Dt, Tamilnadu, India.

${ }^{3}$ Professor and Head of the Department, Department of Anatomy. Karpaga Vinayaga Institute of Medical Sciences, Madurantakam Taluk, Chengalpet Dt, Tamilnadu, India.

\section{ABSTRACT}

Introduction: Spleen is the largest and secondary lymphoid organ in humans. It has two ends: Anterior and Posterior end. Two surfaces: Visceral and Diaphragmatic surfaces. Three borders: Superior, Inferior and Intermediate.Spleen begins to develop during the $5^{\text {th }}$ week ofintra-uterine life from a mass of mesenchymal cells, originating in the dorsal mesogastrium as a localized thickening of coelomic epithelium. The spleen is lobulated in foetus but the lobules normally disappear before birth. The imperfect fusion of splenic masses during embryonic life results in an accessory spleen. The spleen plays a vital role in regard to blood storage, formation of lymphocyte and defense against foreign particles.

Materials and methods: The study was carried out in 50 formalin fixed spleen from the Department of Anatomy, KarpagaVinayaga Institute of Medical Sciences, Madurantakam Taluk, Chengalpet Dt, Tamilnadu, India.

Results: Out of 50 spleens, Wedge shape is seen in 33 spleens, Triangular shape is observed in 5 spleens, tetrahedral in 7 spleens, oval shape in 3 spleens, and dome-shaped in 2spleen. The splenic notches were observed in the superior border in 44 spleens (88\%) and notch seen in the inferior border in 4 spleens (8\%) and the absence of a notch in both the superior and inferior border noted in 2 spleens (4\%). The number of notches on the superior border is from 1 to 4 and the number of notches on the inferior border is 1 . Fissures noted in 8 spleens(16\%). In 5 specimens fissures extended to reach the visceral surface.

Conclusion:The presence of abnormal fissures and lobes of the spleen might confuse the radiologists. Abnormal lobulation might cause misinterpretation as mass originating from the kidney. It is essential for surgeons and radiologists to be aware of the splenic variations.

KEY WORDS: splenic surfaces, shapes, notches, fissures.

Corresponding Author: Dr. Precila Infant Vincy. V, M.D. Anatomy Post graduate, Karpaga Vinayaga Institute of Medical Sciences, Madurantakam Taluk, Chengalpet Dt, Tamilnadu, India.

E-Mail: Pivtulip@gmail.com

Access this Article online

Quick Response code

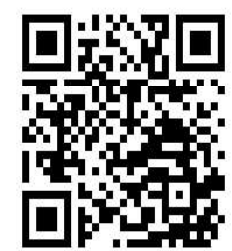

DOI: $10.16965 /$ ijar.2021.145
Journal Information

International Journal of Anatomy and Research

ISSN (E) 2321-4287 | ISSN (P) 2321-8967

https://www.ijmhr.org/ijar.htm

DOI-Prefix: https://dx.doi.org/10.16965/ijar

\section{Article Information}

Received: 30 May 2021

Peer Review: 30 May 2021

Revised: 12 Jul 2021
Accepted: 12 Jul 2021

Published (O): 05 Aug 2021

Published (P): 05 Sep 2021

\section{INTRODUCTION}

Spleen is the largest and secondary lymphoid organ in human. Spleen has both hematological and immunological function as it related to circulatory and lymphoid system. It is located in the left hypochondrium between the greater curvature of stomach and left colic flexure. Spleen is a subdiaphragmatic organ. The shape of the spleen varies from wedge shape to tetrahedral. Spleen has two ends, two surfaces, and three borders. The two ends are anterior and posterior. The three borders are 
superior, inferior and intermediate[1].

The two surfaces are visceral and diaphragmatic surface. Visceral surface has gastric, renal, colon and pancreatic impressions. The diaphragmatic surface may have the impressions of 9, 10, 11 ribs of the left side. The axis of the spleen coincides with the left tenth rib[2].

Spleen begins to develop during the $5^{\text {th }}$ week of intra uterine life from a mass of mesenchymal cells, originating in the dorsal mesogastrium as a localized thickening of coelomic epithelium.The spleen develops as a lobule and the lobules fused to form the adult spleen. The notches on the superior border shows the lobulated development of spleen[3]. The spleen pushed to the left side during the rotation of stomach.

The failure of fusion of splenic masses during embryonic life results in an accessory spleen. The accessory spleen of splenic tissue also found in hilum of the spleen, greater omentum, gastro-splenic ligament and rarely in spermatic cords [1].

The Spleen plays a vital role regarding blood storage, formation of lymphocytes, and defense against foreign particles.Spleen contains one third of total body platelets and neutrophils. The sequestered cells are available when needed during bleeding or infection [2].

Spleen is known as the graveyard of RBC's as it filters blood by removing mature and old erythrocytes from circulation.

\section{Aims and Objectives:}

To study about the various shapes of the spleen, notches on the borders and fissures on the surfaces of the spleen.

\section{MATERIALS AND METHODS}

The study was carried out in 50 formalin fixed spleen from the Department of Anatomy in our college. The presence and number of notches on the superior, inferior and intermediate border were noted. The presence of fissure on the diaphragmatic and the visceral surface were also noted. The different shapes of the spleen were observed carefully and tabulated.

\section{RESULTS}

In the present study, we have observed 5 different shapes of the spleen. Out of 50 spleens, Wedge shape is seen in 33 spleens, Triangular shape is observed in 5 spleens, tetrahedral in 7 spleens, oval shape in 3 spleens and dome-shaped in 2 spleen. (Table 1 \& Figure 1)

Table 1: Percentage of various shapes of the spleen.

\begin{tabular}{|cc}
\hline Shape & Percentage \\
\cline { 2 - 2 } Wedge & $66 \%$ \\
\hline Tetrahedral & $14 \%$ \\
Triangular & $10 \%$ \\
Oval & $6 \%$ \\
Dome & $4 \%$ \\
\hline
\end{tabular}

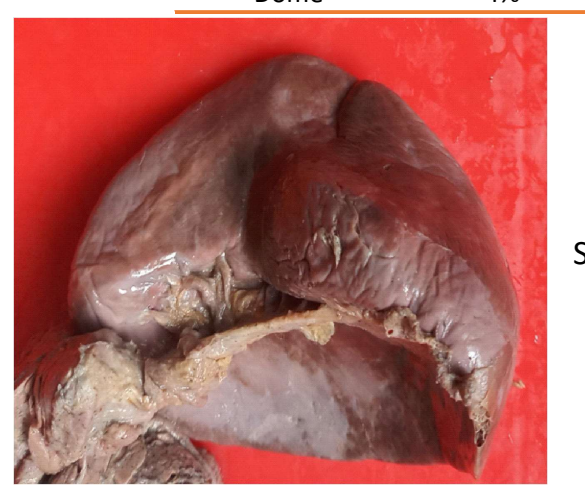

Fig. 1:Wedge Shaped Spleen.

Splenic Notches:Out of 50 specimens, Splenic notches were found on the superior border in 44 spleens and notches were seen on the inferior border in 4 spleens. The absence of notch on all the three borders is noted in 2 spleens. (Chart $1 \&$ Figure 2)

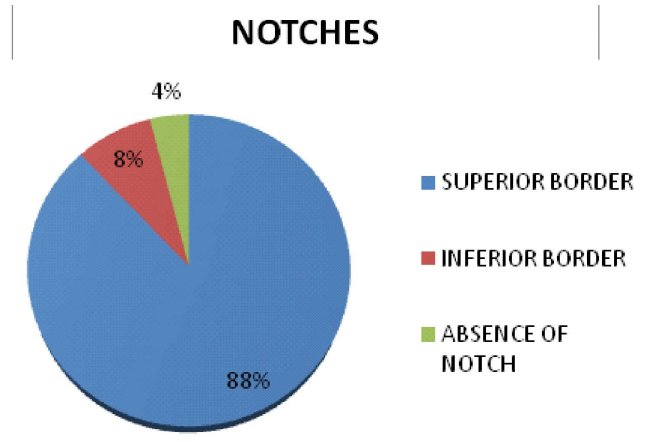

Chart 1:Percentage of notches present on the borders of the spleen:

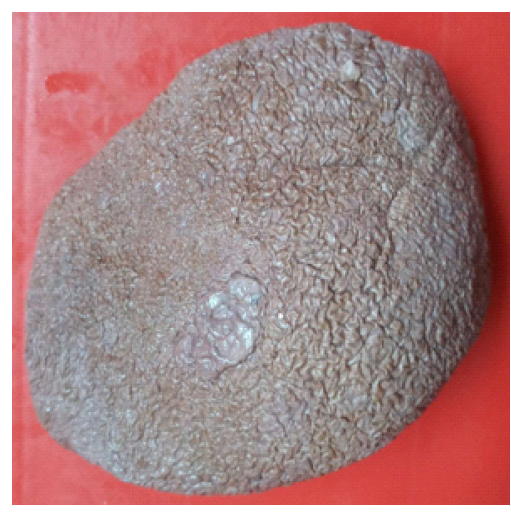

Fig. 2:Absence of notch 
Number of Notches:We have observed the number of notches on the superior border varied from 1 to 4 and the number of notches on the inferior border is 1 . Single notch on the superior border is observed in 22 spleens and the least observed is 4 notches on the superior border in 4 spleens. (Chart 2 \& Figure 3)

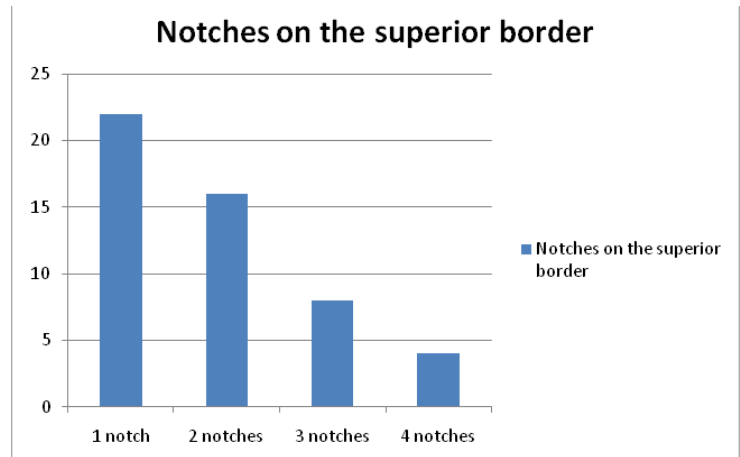

Chart 2: number of spleens with notches on the superior border.

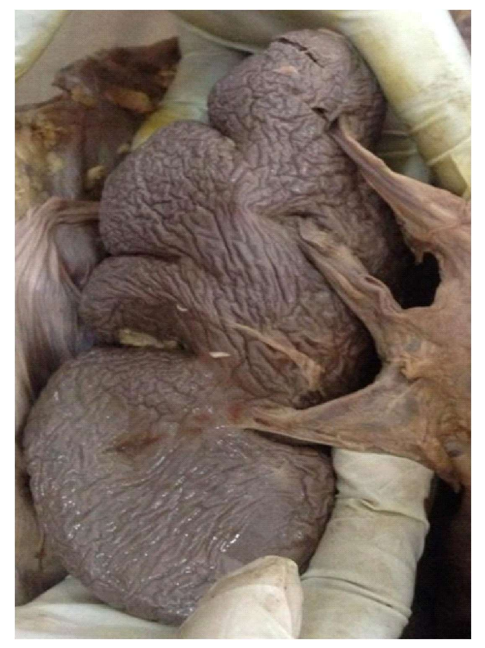

Fig. 3:Splenic notches on superior border.

Splenic Fissures:Fissures were noted in 8 spleens(16\%) out of 50 . In three specimens fissures were present in the diaphragmatic surface alone. In five specimens it extended from the visceral surface to reach the diaphragmatic surface. (Figure 4)

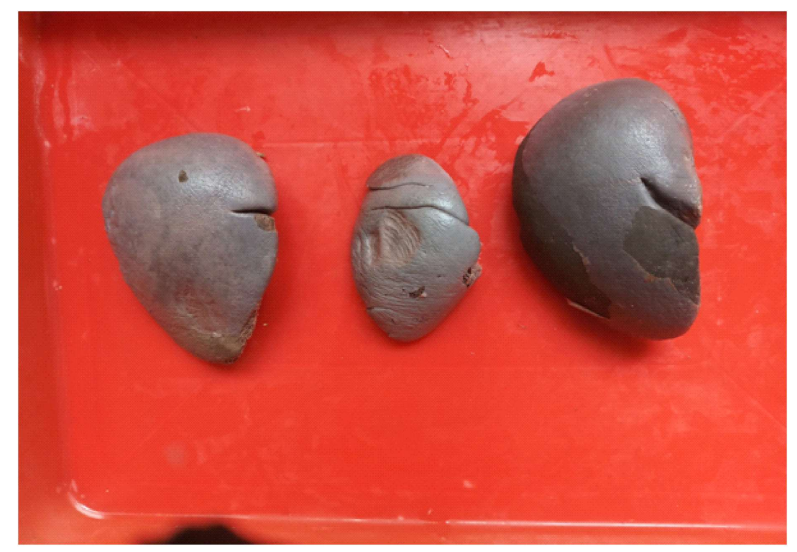

Fig. 4:Fissures extending on both the surfaces.

\section{DISCUSSION}

The Spleen is the large encapsulated mass of vascular and lymphoid tissue. The Spleen is a variable organ with respect to its shape, size, notches and fissures[1].

In the present study, we have noted 5 different shapes of the spleen.The shape may vary due to the visceral impressions of the neighbouring structures. The shape of the spleen is tetrahedral when the colic impression on the visceral surface is prominent[2]. The comparison of the percentage of the shape of the spleen with previous studies is illustrated in chart 3.

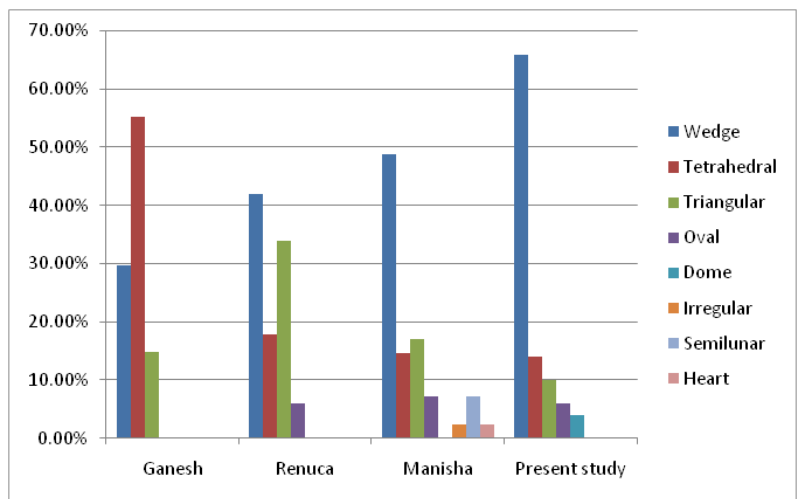

Chart 3:Comparison of percentage of various shapes of the spleen with previous studies

The most common shape of the spleen in the present study is wedge shape which correlates with the study of Renuca[4] and Manisha[5]. Manisha[5] et al reported semilunar and heart shape in their study which is not observed in the present study. Ganesh et al [6] have observed the maximum number of tetrahedral-shaped spleen in their study than wedge shape.

The notches in the superior border of the adult spleen are remnants of the grooves that separated the fetal lobules[3]. As per the standard textbooks, the splenic notches usually present in the superior border and the inferior border will be blunt. In the present study, we have noted notches in the inferior border. Bhumica et al[7] has observed $8.3 \%$ of notches in the inferior border. The percentage of splenic notches in all three borders of the spleen is compared with previous studies and tabulated in table 2 .

In the present study, the number of notches on the superior border varies from 1 to 4 . 
A. Thamaraiselvi, Precila Infant Vincy. V, T.L. Anbumani. Morphological Study of Splenic Notches and Fissures

Table2:Shows comparison of percentage of splenic notches with previous studies:

\begin{tabular}{cccc}
\hline Previous studies & $\begin{array}{c}\text { Percentage of notches } \\
\text { in superior border }\end{array}$ & $\begin{array}{c}\text { Percentage of notches in } \\
\text { inferior border }\end{array}$ & $\begin{array}{c}\text { Percentage of notches in } \\
\text { intermediate border }\end{array}$ \\
\hline Das et al [9] & $98 \%$ & $2 \%$ & - \\
\hline Sunil et al [13] & $85 \%$ & $5 \%$ & - \\
Bhumica et al [7] & $85 \%$ & $8.30 \%$ & - \\
\hline Present study & $88 \%$ & $8 \%$ & \\
\hline
\end{tabular}

Parson[8] mentioned the spleen with two notches being the most common and he observed the range of 0 to 7 splenic notches in his study. Das et al [9] reported upto 4 notches in their study. Thanya et al [10] reported nine notches and Gandhi et al [11] reported six notches.

Normally spleen is not palpable but when enlarged two to three time of its size it is palpable. Splenomegaly is a symptom of various hematological, immunological, and infectious diseases [12]. The enlarged spleen is detected by palpating the splenic notches. The absence of notches on the superior border may result in difficulty while palpating the spleen [13]. Splenomegaly in unnotched spleens may be misdiagnosed as renal swellings.

In the present study, fissures were seen in 8 spleens. The fissures on the diaphragmatic surface may be due to a developmental defect or linked to any mechanical pressure of the surrounding structures[9]. The presence of fissures in the spleen may be misinterpreted as splenic lacerations. Smidt [14] observed a case of a large congenital fissure mimicking splenic hematoma in splenic scintigraphy.

The most common congenital anomaly of the spleen is the accessory spleen. The most common site of the accessory spleen is near the splenic hilum. The accessory spleens may mistake for tumors [15].

\section{CONCLUSION}

The spleen is closely related to the left kidney and suprarenal glands. The presence of abnormal fissures and lobes of the spleen might confuse the radiologists. Abnormal lobulation might cause misinterpretation as mass originating from the kidney. It is essential for clinicians, surgeons and radiologists to be aware of the splenic variations to avoid misinterpretations in arriving at the diagnosis.

\section{Conflicts of Interests: None}

\section{REFERENCES}

[1]. Standring S: Gray's Anatomy: The Anatomical Basis of Clinical Practice, 40th edition. Chapter 71. Edinburg: Elsevier Churchill Livingstone, 2010; 1191-97.

[2]. A.K.Datta, Essentials of human anatomy: Thorax, Abdome and Pelvis. $10^{\text {th }}$ edition, Current books international:2018. p.227-232

[3]. Moore KL, Dally AF. Clinically oriented anatomy. 7th ed. Philadelphia:Lippincott Williams \& Wilkins; 2011: p. 167.

[4]. Renuca Karam, Wahengbam S, Devi KA, Gangmei $G$, Remei $E$, et al. Human spleen-a study of its morphological variations. Int J Anat Res. 2018;6(4.2):5840-3.

[5]. Manisha S More, Manoj D Togale, Shilpa Bhimalli. Morphometric study of human adult cadaveric spleen. Medpusle Int J Anat. 2019;11(1):11-8.

[6]. Ganesh TrimbakWaghmode, SukhanandPorwal S, Bharat Shinde P, TrimbakWaghmode U, S.R. et al. Morphological analysis of variations of spleen. Int J Anat Res. 2017;5(2.1):3693-7.

[7]. Bhumica Dang, Malik VS, Gupta S, Chhabra S et al. Variations in splenic notches and fissures: Study with clinical importance. Int J Anat Res. 2018;6(1.1):4803-5.

[8]. Parsons FG. Notches and fissures of the spleen. J Anat Physiol. 1901;35(Pt 3):416-27.

[9]. Das S, Abd Latiff A, Suhaimi FH, Ghazalli H, Othman F. Anomalous splenic notches: a cadaveric study with clinical importance. Bratisl Lek Listy. 2008;109(11):513-16.

[10]. Thanya.I.Pathirana, Matthew J. Barton, Mark George, Mark R. Forwood, SujeewaP.W.Palagama. A rare anomaly of the human spleen with nine notches associated with multiple accessory spleens. A case study, hypothesis on origin and review of clinical significance. Italian journal of Anatomy and Embryology. 2016:121(2):188-197.

[11]. Gandhi KR, Chavan SK, Oommen SA. Spleen with multiple notches: A rare anatomical variant with its clinical significance. Int J Stud Res 2013;3:24-5.

[12]. Arumugam S, Subbiah NK. A cadaveric study of splenic fissures and bilobed spleen. Sultan Qaboos Univ Med J. 2020;20(4):46-51. 
A. Thamaraiselvi, Precila Infant Vincy. V, T.L. Anbumani. Morphological Study of Splenic Notches and Fissures.

[13]. Sunil et al A Study on Splenic Notches in Adult Human Cadavers - its Clinical Importance, IOSR Journal of Dental and Medical Sciences. 2016;15(12):115-118.

[14]. Kevin Paul Smidt, M.B, Splenic scintigraphy: A large congenital fissure mimicking splenic hematoma. Radiology. 1977;122(1):169.
[15]. Mohammadi Shabnam, Hedjazi A, Sajjadian M, Ghrobi N, Moghadam M, Mohammadi M. Accessory spleen in the splenic hilum: A cadaveric study with clinical significance. Med Arch. 2016;70(5):389.

How to cite this article:

A. Thamaraiselvi, Precila Infant Vincy. V, T. L. Anbumani. Morphological Study of Splenic Notches and Fissures. Int J Anat Res 2021;9(3.2):8064-8068. DOI: 10.16965/ijar.2021.145 